\title{
Psychosocial and Cultural Determinants of Interest and Uptake of Skin Cancer Genetic Testing in Diverse Primary Care
}

\author{
Jennifer L. Hay ${ }^{a}$ Kirsten Meyer White ${ }^{b}$ Andrew Sussman ${ }^{b}$ Kim Kaphingst $^{c}$ \\ Dolores Guest $^{\mathrm{b}} \quad$ Elizabeth Schofield ${ }^{\mathrm{a}} \quad$ Yvonne T. Dailey $^{\mathrm{b}}$ Erika Robers $^{\mathrm{b}}$ \\ Matthew R. Schwartz ${ }^{b}$ Kate Zielaskowski ${ }^{a}$ Yuelin Li $^{\mathrm{a}}$ David Buller ${ }^{\mathrm{d}}$ \\ Keith Hunley ${ }^{b}$ Marianne Berwick ${ }^{b}$ \\ ${ }^{a}$ Memorial Sloan Kettering Cancer Center, New York, NY, USA; b University of New Mexico, Albuquerque, NM, USA;

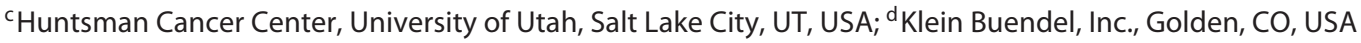

\section{Keywords \\ Culture $\cdot$ Psychosocial factors · Primary care $\cdot$ Hispanics · \\ Skin cancer risk}

\begin{abstract}
Background: Translational research in genomics has limited reach and requires efforts to broaden access and utility in diverse populations. Skin cancer is common and rates are rising, including among Hispanics. Germline variants in the melanocortin-1 receptor $(M C 1 R)$ gene are common in the population and confer moderate risk for melanoma and basal cell cancers across skin types. Feedback about MC1R risk status may promote skin cancer risk awareness and risk reduction. Aims: We examined the level of interest in pursuing $M C 1 R$ testing, and patterns of interest across skin cancer perceived threat and control attitudes, cultural beliefs (family influence on health, health system distrust, cancer fatalism, skin cancer misconceptions), and health literacy. Methods: We used a study website to inform primary care patients in Albuquerque, NM about the benefits and drawbacks of $M C 1 R$ testing. Website logon, request of a saliva test kit, and return of the test kit (yes vs. no) were primary assessments of
\end{abstract}

study interest and uptake. Results: Of 499 participants provided with a test offer, $33 \%$ requested and returned the test. Lower family influence on participants' health was an important factor both overall and within ethnicity subgroups, and may indicate that primary care patients interested in skin cancer genetic testing see themselves as proactive health seekers, independent from family encouragement. Lower self-efficacy for skin cancer prevention was also an important characteristic of those who tested. Conclusion: As evidence for common genetic markers for skin cancer accumulates, these findings suggest characteristics of those most likely to pursue genetic testing for skin cancer risk.

() 2019 S. Karger AG, Basel

\section{Introduction}

Translational research involving the application of genomic technologies to the medical needs of individuals has yet to reach diverse populations who stand to benefit from such technologies [1]. A 2016 report from the National Academy of Sciences highlighted the pressing need to address issues of access to genomic medicine [2]. One

\section{KARGER}

(c) 2019 S. Karger AG, Basel

E-Mail karger@karger.com

www.karger.com/phg
Jennifer L. Hay, PhD

Psychiatry and Behavioral Sciences

Memorial Sloan Kettering Cancer Center

1275 York Avenue, New York, NY 10065 (USA)

E-Mail hayj@mskcc.org 
setting where translational research is poised to impact public health is skin cancer prevention. Skin cancer is common, in contrast to other cancers, and skin cancer rates - including melanoma, the most deadly form of skin cancer - are on the rise [3]. This is true in non-Hispanic whites as well as Hispanics from some locations, such as Florida and California [4-8].

We propose that providing feedback regarding inherited variation in the melanocortin-1 receptor $(M C 1 R)$ gene holds promise as a tool to motivate sun protection and skin cancer screening [9]. This is due to the following characteristics of $M C 1 R$. First, inheritance of specific $M C 1 R$ variants is a robust marker of increased risk of melanoma and keratinocyte skin cancers [10-13]. Second, there is a high prevalence of variant carriers in the population $(60 \%)[9,13]$, making testing highly relevant in the general population. Third, there is particular relevance of carrier status to those at low phenotypic risk who may not otherwise appreciate their skin cancer risk $[13,14]$. Attributable risk, the disease reduction possible through "removal" of a specific exposure, to the carriage of one of the nine most prevalent $M C 1 R$ variants ranges from 1.2 to $8.9 \%$ and approaches $40 \%$ when summed across variants [13]. The risk attributable to $M C 1 R$ variants is 30 and $45 \%$ for basal and squamous cell carcinoma, respectively [12]. Further, a recent metaanalysis [15] showed that genetic testing increased motivation for a range of positive changes in health-protective behaviors, including sun protection, when comparing individuals at higher genetic risk to those at average genetic risk.

While members of racial and ethnic minority groups stand to benefit from genomic technologies, to date, those who pursue personalized genetic information have been disproportionately non-Hispanic white and at higher socioeconomic, education, and literacy levels [16]. Yet diverse and underserved populations report interest in genomics when information is presented in an accessible and culturally relevant way $[17,18]$, and there are promising indications that Hispanics have interest in learning more about their genetic risks of developing cancers [1922]. Examining the patterns in interest and uptake in Hispanics and other underserved populations could reduce disparities in the context of personalized genomics [16, $23,24]$ and reduce health knowledge gaps [25] as well as access to online genomic information given the "digital divide" $[26,27]$ in these populations. Understanding the psychosocial and cultural factors that underlie uptake in diverse populations will allow for the development and testing of theory-based and culturally informed interven-

Psychosocial Determinants of Skin Cancer Genetic Testing tions that enhance accessibility of genomic technologies across broad demographic groups. Genomic testing of $M C 1 R$ for skin cancer risk may promote skin cancer awareness and risk reduction behaviors across ethnically and racially diverse populations [9], especially among Hispanics, who generally have low skin cancer risk awareness [6, 28-32].

The current study was designed to examine levels of interest in pursuing skin cancer genetic testing and patterns of interest across theoretically relevant psychosocial and cultural factors. In a study examining the role of $M C 1 R$ testing interest and longitudinal outcomes in a diverse primary care population in Albuquerque, NM we used a study website to inform interested primary care patients about the benefits and drawbacks of MC1R testing [33]. We found moderately high levels of interest in testing as evidenced by website logon. Most who logged on decided to request testing, and most who requested testing returned the kit. The strongest demographic predictors of website logon were race/ethnicity and education (non-Hispanic whites and more highly educated subjects were more likely to log on); the strongest predictor of ordering the test was sunburn history [34].

Understanding psychosocial and cultural factors that may promote interest in pursuing genomic information will be particularly important in identifying motives for testing that may explain the demographic differences in interest in diverse populations and are more amenable to intervention to improve access. First, perceptions of threat associated with skin cancer, as well as confidence (self and response efficacy) in personal ability to control skin cancer risk (drawn from Protection Motivation Theory [35]), may promote interest in testing for $M C 1 R$. Accordingly, our first research question examines whether perceived skin cancer threat and control beliefs differ by ethnicity and predict interest and uptake of $M C 1 R$ testing. Second, specific cultural beliefs and values related to health promotion, the healthcare system, or skin cancer may influence test interest and uptake. Such values may include a cultural orientation prioritizing family relationships and communication which could galvanize interest in genetic information [36, 37], distrust of the health system that may lead individuals to seek information as to their risk outside of the healthcare system [38, 39], cancer fatalistic beliefs that may reduce interest in any risk information about cancer [40], as well as misconceptions about skin cancer common among Hispanics, and may reduce interest in skin cancer-specific information $[19,41]$. In this second research question we also examined health literacy, since 
use of the Internet for health information drops sharply and directly with health literacy levels [42] and thus low health literacy may inhibit interest in finding out about $M C 1 R$ testing via web information. Accordingly, our second research question involved whether cultural values and beliefs predict interest in and uptake of $M C 1 R$ testing.

\section{Methods}

\section{Participants}

As described previously [33], bilingual project assistants approached primary care patients in the University of New Mexico outpatient primary care clinics with invitation flyers (English and Spanish) and National Cancer Institute skin cancer information for diverse skin types (available in English and Spanish versions; "Anyone can get skin cancer" [43]). Patients were eligible if they had been registered in any University of New Mexico clinic for at least 6 months, had been assigned a University of New Mexico primary care physician, were aged $\geq 18$ years, and were fluent in English or Spanish.

\section{Procedure}

Those who were eligible completed a screener survey that assessed (1) perceived risk for skin cancer on a seven-point absolute verbal likelihood scale ("no chance" to "certain to happen," with a "don't know" response option), (2) perceived importance of learning about your genes and associated health risks on a sevenpoint scale ("not at all important" to "very important" [44]), and (3) demographics and skin cancer risk factors [45]. Those who refused study participation were asked about their reasons for refusal.

Those who were eligible and accepted study participation completed the baseline assessment (see below for measures) and were randomized 1:5 to a usual care condition (National Cancer Institute skin cancer information for diverse skin types, $n=101$ ) or an invitation to go online to learn about skin cancer and genetic testing as well as an offer to test for MC1R $(n=499)$. Usual care participants did not receive an invitation to log on. Participants randomized to the MC1R test offer had the option to log on to the study website to read three educational modules regarding skin cancer and $M C 1 R$ testing and then register a decision regarding whether they wanted to be tested for study participation (see online suppl. Appendix B for website content; for all online suppl. material, see www.karger.com/doi/10.1159/000501985). The website education materials were available in English or Spanish. Those without Internet access were offered the opportunity to view the website materials in paper form. Participants who chose testing were mailed a test kit, and if they so desired, provided a saliva sample for genetic testing.

\section{Outcome Measures}

Participation was tracked based on personalized web links. Website logon, request of a saliva test kit (yes vs. no), and return of a test kit (yes vs. no) were assessed as primary assessments of study interest and uptake. Participants were thus classifiable into one of four outcomes based on the follow-through for testing.

\section{Predictor Measures (Baseline Assessment)}

Perceived skin cancer threat beliefs [46] included three widely used $[47,48]$ assessments of skin cancer risk perceptions. The seven-level absolute verbal likelihood scale ("no chance" to "certain to happen") that was included in the screener survey and a two-level verbal absolute likelihood ("unlikely" or "likely to happen"; assessed at baseline) both included "don't know" response options [49]. During the baseline assessment, a five-level comparative likelihood assessment ("much lower" to "much higher" than individuals of participants' age and sex) was also collected. For all risk measures, higher values indicate higher perceived threat. The pairwise correlations among these three assessments ranged from 0.57 to 0.67 and were all statistically significant (all $p<0.001)$.

Perceived skin cancer control beliefs [46] included skin cancer prevention self-efficacy (seven items, on separate four-point scales; "not at all" to "extremely capable") and skin cancer prevention response efficacy (seven items on separate four-point scales; "not at all" to "extremely important" $[50,51])$. Midway through data collection, the wording for self-efficacy was adjusted due to participant difficulties with the phrase "capable." Based on participant feedback, the item "how capable do you feel that they can regularly perform ..." was changed to "how confident do you feel that you can regularly perform ..." Accordingly, we analyzed the seven self-efficacy items that assessed "capability" and "confidence" separately for the subsamples who were assessed for each. In our sample, the Cronbach alphas for self-efficacy (capable; confident) and response-efficacy were $0.71,0.67$, and 0.85 , respectively.

Family influence on health examined social influences on learning and doing more to maintain their health (e.g., "The people who mean the most to you think you should learn more about ways you can keep yourself healthy"; "Your health choices affect the people who mean the most to you" (four items, seven-point scales, "strongly disagree" to "strongly agree"). The Cronbach alpha for "family influence on health" within our sample was 0.70 . This scale was previously used to examine social influence on health information seeking and behavior change in a National Institutes of Health intramural study examining interest and uptake of $M C 1 R$ and other disease risk genetic variants in a primary care population in Detroit, MI [44].

Health system distrust included nine items such as "the health care system makes too many mistakes" and "the health care system lies to make money," each assessed in five-point scales ("strongly disagree" to "strongly agree"). The Health System Distrust Scale [52] has been validated in primary care against established physician trust scales with good reliability $(0.83)$.

Cancer fatalism [53] included a fifteen-item assessment ("agree", "disagree") with scales examining fear, pessimism, and the inevitability of death in the context of cancer. The scale is well validated and reliable [40]

Skin cancer misconceptions included nine items assessing misconceptions about skin cancer including preventability, treatability, and information overload ("agree", "disagree"); such misconceptions have been described as more prevalent in Hispanics compared to non-Hispanic whites [19]. The items are derived from the Health Information National Trends Survey 2007 [54].

Health literacy was assessed through three items - level of confidence in filling out medical forms independently, frequency of needed assistance reading hospital materials, and frequency of
60

Public Health Genomics 2019;22:58-68 DOI: $10.1159 / 000501985$
Hay et al. 
problems learning about medical conditions because of difficulty reading hospital materials (five-point scales, "not at all/none of the time" to "extremely/all the time" $[55,56])$. This assessment strategy has been found to be highly feasible for use in primary care populations and has a much lower respondent burden compared to other health literacy scales, such as the Test of Functional Health Literacy in Adults or the Rapid Estimate of Adult Literacy in Medicine, as well as good sensitivity across diverse literacy levels [55, 56].

\section{Statistical Approach}

All psychosocial predictor measures were described and compared by ethnicity (Hispanic vs. non-Hispanic) using independent-sample $t$ tests. For the primary outcomes, study interest and uptake, we examined three dichotomous outcomes: (1) website logon, (2) request of a saliva test kit, and (3) return of a test kit (all yes vs. no) in unadjusted and adjusted logistic regression models. In addition to the psychosocial and cultural factor predictors, we included several factors shown to be important to study interest and uptake in our prior work (ethnicity, education, and sunburn history [34]). We also examined intercorrelation between all psychosocial predictor measures.

Given that logistic regression models for the downstream outcomes of kit request and kit return have reduced statistical power due to the conditional nature of the denominator (e.g., only those who order a test kit are included in analyses regarding kit return), all four stages of test follow-through were combined into a single model. Test follow-through was quantified as a number ranging from 0 to 3 by whether the participant never logged on $(0)$, logged on but did not request a kit (1), requested but did not return a kit (2), or requested and returned a kit (3). Psychosocial measures were then examined for association with test follow-through unadjusted and adjusted associations using a series of ordinal logistic regression models. In these ordinal logistic regression models [57], a single odds ratio $(\mathrm{OR})$ is estimated for each predictor and represents the odds of greater test follow-through with a one-point increase in the predictor.

In addition to the standard logistic models, we employed a wellestablished data mining approach to identify "risk" groups for the test follow-through outcome. We first used classification and regression tree (CART [58]) models, which are well suited to identify subtle differential findings by demographic group because all combinations of potential risk factors are considered to produce the optimal classification tree and thus the most important predictors. Participants are classified into discrete groups based on similarities of both covariate and outcome profiles; that is, the most discriminating predictors are found to explain the outcome, and participants are grouped accordingly. Finally, random forest models [59] were used to confirm CART analytic results. Random forest models identify the most important predictors of test followthrough, revealing less detailed results than the CART analysis but providing robustness against random variation in the data mining algorithms by repeated sampling. Both CART and random forest models are data-driven so that risk groups are identified that minimize the mean squared error (MSE) of predicted outcomes. These data mining approaches provide insight into the most discriminating observed factors with respect to test follow-through regardless of a priori risk factor hypotheses. All statistical analyses were conducted in SAS (Cary, NC, USA) version 9.4 and the R "randomForest" package [60].

Psychosocial Determinants of Skin Cancer Genetic Testing

\section{Results}

Of the 726 eligible individuals approached for this study, 105 refused participation and 21 consented but never completed the baseline assessment and were thus not randomized (passive refusers); 600 consented and were randomized. Both perceived skin cancer absolute risk $(\mathrm{OR}=1.52,95 \% \mathrm{CI} 1.22-1.89)$ and interest in learning about genes $(\mathrm{OR}=1.31,95 \% \mathrm{CI} 1.13-1.52)$ were directly related to study acceptance, such that participants higher in perceived skin cancer risk or interest in learning about genes were more likely to participate in the study $(p<0.001)$. Participants who answered "don't know" to the seven-level absolute perceived skin cancer risk question were less likely to participate in the study than patients who gave a valid scale response $(\mathrm{OR}=0.48$, 95\% CI 0.23-0.97, $p<0.05)$. These differences in risk perceptions, use of "don't know" responses, and interest in learning about genes were significant after adjustment for ethnicity and education, which were found to be important demographic predictors of study acceptance [34].

Of the 600 individuals enrolled in the trial, this paper included only the 499 participants randomized to MC1R test offer. Participants reported their perceived risk of skin cancer as being about average; only $24 \%$ rated their comparative risk as being above average. Family influence on health scores was high among the sample, with a mean of 22.15 on a scale of $0-28$ and $69 \%$ of participants scoring at least 21.0. Notably, Hispanics reported significantly lower absolute (mean $=3.73$ vs. $4.20, p<0.001$ ) and comparative perceived skin cancer risk (mean $=2.63$ vs. $3.09, p<0.001$ ), perceived control over skin cancer risk (mean $=22.87$ vs. $24.31, p=0.009$ ), and health literacy (mean $=10.21$ vs. $11.04, p<0.001)$ than non-Hispanic participants ( $86 \%$ of whom were white). Hispanics responded "don't know" for absolute risk more frequently than non-Hispanics ( 43 vs. $29 \%, p=0.002$ ). Hispanics reported significantly higher family influence on health (mean $=22.61$ vs. 21.72, $p=0.047$ ), cancer fatalism (mean $=4.47$ vs. $3.13, p<0.001$ ), and skin cancer misconceptions (mean $=2.69$ vs. $1.83, p<0.001$ ) compared to non-Hispanics. See Table 1 for further description of psychosocial variables.

Of the 499 participants offered website logon, the largest proportion either never logged on to the website at all (54\%) or participated fully by logging on, requesting, and then returning a kit (33\%). In unadjusted logistic models examining website logon (yes vs. no), higher two-level absolute risk (OR $=1.87,95 \%$ CI 1.20-2.93), 
Table 1. Psychosocial variables, overall and by ethnicity

\begin{tabular}{|c|c|c|c|c|c|c|c|}
\hline Measure & Range & $n$ & All & $\begin{array}{l}\text { Hispanic }^{\mathrm{a}} \\
(n=242)\end{array}$ & $\begin{array}{l}\text { Non-Hispanic } \\
(n=255)\end{array}$ & $d\left(\chi^{2}\right)$ & $p$ value $^{\mathrm{b}}$ \\
\hline Perceived risk (absolute - 7-level) & $1-7$ & 447 & $3.98(1.4)$ & $3.73(1.4)$ & $4.20(1.4)$ & 0.33 & 0.0005 \\
\hline Don't know on absolute risk ${ }^{\mathrm{c}}$ & & 497 & $10 \%$ & $13 \%$ & $7 \%$ & $(3.94)$ & 0.0471 \\
\hline Perceived risk (absolute - 2-level) & $0-1$ & 318 & $0.52(0.5)$ & $0.40(0.5)$ & $0.61(0.5)$ & 0.42 & 0.0002 \\
\hline Don't know on absolute risk ${ }^{\mathrm{c}}, \%$ & & 495 & $36 \%$ & $43 \%$ & $29 \%$ & $(9.96)$ & 0.0016 \\
\hline Self-efficacy: capability & $14-28$ & 151 & $23.60(3.4)$ & $22.87(3.4)$ & $24.31(3.3)$ & 0.44 & 0.0085 \\
\hline Self-efficacy: confidence & $7-28$ & 345 & $22.61(3.7)$ & $22.28(3.8)$ & $22.88(3.6)$ & 0.16 & 0.1315 \\
\hline Family influence on health & $4-28$ & 497 & $22.15(5.0)$ & $22.61(4.8)$ & $21.72(5.1)$ & 0.18 & 0.0471 \\
\hline Health system distrust & $9-42$ & 498 & $20.43(6.6)$ & $20.16(6.6)$ & $20.65(6.7)$ & 0.07 & 0.4128 \\
\hline Cancer fatalism & $0-15$ & 492 & $3.79(2.7)$ & $4.47(2.9)$ & $3.13(2.4)$ & 0.50 & $<0.0001$ \\
\hline Skin cancer misconceptions & $0-7$ & 489 & $2.24(1.3)$ & $2.69(1.4)$ & $1.83(1.1)$ & 0.68 & $<0.0001$ \\
\hline
\end{tabular}

Values are presented as mean (standard deviation) unless indicated otherwise. ${ }^{\text {a }}$ Includes participants who said they were Hispanic, Latino, or of Spanish descent; 2 individuals did not report ethnicity. ${ }^{b}$ Based on $t$ tests comparing means across ethnicity groups for continuous variables, and $\chi^{2}$ tests with one degree of freedom for dichotomous ("don't know") variables. ${ }^{c}$ Dichotomous indicators of whether the participant used a "don't know" option in the perceived risk item.

higher comparative perceived risk $(\mathrm{OR}=1.26,95 \% \mathrm{CI}$ 1.04-1.52), higher health literacy $(\mathrm{OR}=1.12,95 \% \mathrm{CI}$ $1.02-1.22)$, lower family influence on health $(\mathrm{OR}=0.95$, 95\% CI 0.91-0.98), and fewer skin cancer misconceptions ( $\mathrm{OR}=0.77,95 \%$ CI $0.67-0.88)$ were all associated with an increased likelihood of logging on to the website. Apart from skin cancer misconceptions, all measures have similar effect estimates with "test follow-through" as assessed by ordinal logistic regression models. Additionally, lower cancer fatalism (OR $=0.93,95 \%$ CI $0.88-$ 0.995) was associated with test follow-through in the unadjusted model and had consistent, though not significant, effect estimates across the dichotomous outcome models (OR range for cancer fatalism: 0.90-0.96). However, in all models adjusted for ethnicity, education, and sunburn history, only skin cancer prevention self-efficacy ("capability") was significantly inversely associated with the dichotomous outcome of requesting a kit; that is, individuals who indicated they were more capable of using sun-protective behaviors were less likely to request a kit. The results of all adjusted logistic models are shown in Table 2.

The best-fit CART model contained five decision points and six distinct risk groups, as depicted in Figure 1. Notably, the tree is not symmetric, such that after dividing the sample by ethnicity, different predictors are important. For non-Hispanic whites, the important predictors of test follow-through were family influence on health and comparative perceived risk. For Hispanics, the important predictors were family influence on health and education. Those with the lowest test follow-through were Hispanic with a high school degree or less; in this group, $73 \%$ did not $\log$ on to the website and only $12 \%$ returned a kit. Hispanics who had higher education and low family influence on health scores exhibited higher test follow-through, and $36 \%$ returned a kit for testing. The group with the highest test follow-through were non-Hispanic whites with low family influence on health, of whom $68 \%$ returned a kit for testing and only $22 \%$ did not log on. The random forest analytic results were consistent with the CART model. Education, comparative perceived risk, and family influence on health were identified as the most important variables for predicting test follow-through, as omission of these resulted in MSE increases of 15.4, 11.3, and 11.4\%, respectively. The next most important predictor was ethnicity (6.2\% increase in MSE); other predictors were associated with minimal changes in MSE of $<2 \%$.

Importantly, family influence on health had modest significant relationships with skin cancer misconceptions, health system distrust, and health literacy, such that those with a higher family influence on health had more skin cancer misconceptions, less distrust, and lower health literacy (correlations: $0.13,-0.14$, and -0.18 , respectively, all $p$ values $<0.01$; see online suppl. Appendix C). Family influence was unrelated to other psychosocial variables. 
Table 2. Predictors of website logon, test request, test return, and overall test follow-through, including both unadjusted and demographics-adjusted models

\begin{tabular}{|c|c|c|c|c|c|}
\hline \multirow[t]{2}{*}{ Measure } & \multirow[t]{2}{*}{ Model outcome } & \multicolumn{2}{|c|}{ Dichotomous outcomes } & \multicolumn{2}{|c|}{ Follow-through outcome } \\
\hline & & $\begin{array}{l}\text { unadj. OR } \\
(95 \% \mathrm{CI})\end{array}$ & $\begin{array}{l}\text { demo. adj. OR } \\
(95 \% \text { CI })\end{array}$ & $\begin{array}{l}\text { unadj. OR } \\
(95 \% \mathrm{CI})\end{array}$ & $\begin{array}{l}\text { demo. adj. OR } \\
(95 \% \mathrm{CI})\end{array}$ \\
\hline \multirow{3}{*}{$\begin{array}{l}\text { Perceived risk (absolute - } \\
\text { 7-level) }\end{array}$} & Logged on & $1.08(0.95,1.23)$ & $1.01(0.87,1.16)$ & \multirow[t]{3}{*}{$1.08(0.96,1.23)$} & \multirow[t]{3}{*}{$1.00(0.87,1.14)$} \\
\hline & Requested & $1.21(0.90,1.61)$ & $1.10(0.81,1.49)$ & & \\
\hline & Returned & $0.98(0.73,1.32)$ & $0.81(0.58,1.13)$ & & \\
\hline \multirow{3}{*}{$\begin{array}{l}\text { "Don't know" on absolute - } \\
\text { 7-level risk }\end{array}$} & Logged on & $0.98(0.54,1.76)$ & $1.38(0.74,2.57)$ & \multirow[t]{3}{*}{$0.88(0.50,1.55)$} & \multirow[t]{3}{*}{$1.18(0.65,2.14)$} \\
\hline & Requested & $1.49(0.33,6.74)$ & $1.96(0.41,9.37)$ & & \\
\hline & Returned & $0.31(0.12,0.80)$ & $0.30(0.11,0.82)$ & & \\
\hline \multirow{3}{*}{$\begin{array}{l}\text { Perceived risk (absolute - } \\
\text { 2-level) }\end{array}$} & Logged on & $1.87(1.20,2.93)$ & $1.69(1.04,2.73)$ & \multirow[t]{3}{*}{$1.93(1.26,2.96)$} & \multirow[t]{3}{*}{$1.74(1.10,2.75)$} \\
\hline & Requested & $0.65(0.23,1.83)$ & $0.67(0.22,2.08)$ & & \\
\hline & Returned & $1.89(0.74,4.81)$ & $1.46(0.53,4.00)$ & & \\
\hline \multirow{3}{*}{$\begin{array}{l}\text { "Don't know" on 2-level } \\
\text { absolute risk }\end{array}$} & Logged on & $0.93(0.64,1.34)$ & $1.10(0.75,1.63)$ & \multirow[t]{3}{*}{$0.86(0.60,1.22)$} & \multirow[t]{3}{*}{$1.05(0.72,1.52)$} \\
\hline & Requested & $1.47(0.66,3.28)$ & $1.13(0.48,2.66)$ & & \\
\hline & Returned & $0.61(0.30,1.26)$ & $0.62(0.29,1.33)$ & & \\
\hline \multirow{3}{*}{$\begin{array}{l}\text { Perceived risk (comparative - } \\
\text { 5-level) }\end{array}$} & Logged on & $1.26(1.04,1.52)$ & $1.05(0.85,1.29)$ & \multirow[t]{3}{*}{$1.30(1.08,1.56)$} & \multirow[t]{3}{*}{$1.06(0.87,1.30)$} \\
\hline & Requested & $1.36(0.91,2.04)$ & $1.08(0.68,1.71)$ & & \\
\hline & Returned & $1.36(0.93,1.98)$ & $1.12(0.73,1.70)$ & & \\
\hline \multirow[t]{3}{*}{ Response efficacy } & Logged on & $1.06(1.00,1.11)$ & $1.04(0.99,1.10)$ & \multirow[t]{3}{*}{$1.05(1.01,1.11)$} & \multirow[t]{3}{*}{$1.04(0.99,1.09)$} \\
\hline & Requested & $0.97(0.86,1.08)$ & $0.98(0.87,1.10)$ & & \\
\hline & Returned & $1.00(0.91,1.09)$ & $1.03(0.93,1.14)$ & & \\
\hline \multirow[t]{3}{*}{ Self-efficacy: capability } & Logged on & $1.15(1.03,1.27)$ & $1.10(0.99,1.23)$ & \multirow[t]{3}{*}{$1.11(1.01,1.22)$} & \multirow[t]{3}{*}{$1.07(0.96,1.18)$} \\
\hline & Requested & $0.71(0.50,1.02)$ & $0.66(0.44,0.98)$ & & \\
\hline & Returned & $0.97(0.77,1.23)$ & $0.98(0.76,1.25)$ & & \\
\hline \multirow[t]{3}{*}{ Self-efficacy: confidence } & Logged on & $1.02(0.96,1.08)$ & $1.01(0.95,1.07)$ & $1.02(0.97,1.08)$ & $1.00(0.95,1.06)$ \\
\hline & Requested & $0.99(0.87,1.12)$ & $0.94(0.82,1.07)$ & & \\
\hline & Returned & $1.01(0.90,1.13)$ & $0.99(0.88,1.11)$ & & \\
\hline Family influence on health & Logged on & $0.95(0.91,0.98)$ & $0.96(0.92,1.00)$ & $0.95(0.92,0.99)$ & $0.97(0.93,1.00)$ \\
\hline & Requested & $1.04(0.97,1.12)$ & $1.07(0.99,1.16)$ & & \\
\hline & Returned & $0.95(0.88,1.03)$ & $0.96(0.89,1.04)$ & & \\
\hline Health system distrust & Logged on & $1.00(0.97,1.03)$ & $1.00(0.97,1.02)$ & $1.00(0.98,1.03)$ & $1.00(0.97,1.02)$ \\
\hline & Requested & $1.05(0.99,1.12)$ & $1.05(0.99,1.13)$ & & \\
\hline & Returned & $0.99(0.94,1.05)$ & $0.99(0.94,1.05)$ & & \\
\hline Cancer fatalism & Logged on & $0.96(0.90,1.02)$ & $1.01(0.94,1.09)$ & $0.93(0.88,1.00)$ & $0.99(0.93,1.06)$ \\
\hline & Requested & $0.85(0.73,0.98)$ & $0.92(0.78,1.08)$ & & \\
\hline & Returned & $0.84(0.73,0.96)$ & $0.88(0.76,1.02)$ & & \\
\hline Skin cancer misconceptions & Logged on & $0.77(0.67,0.89)$ & $0.89(0.76,1.04)$ & $0.75(0.65,0.86)$ & $0.88(0.76,1.03)$ \\
\hline & Requested & $0.79(0.58,1.08)$ & $1.04(0.73,1.48)$ & & \\
\hline & Returned & $0.79(0.59,1.07)$ & $0.88(0.63,1.22)$ & & \\
\hline Health literacy & Logged on & $1.12(1.02,1.22)$ & $1.03(0.93,1.14)$ & $1.13(1.03,1.24)$ & $1.04(0.94,1.15)$ \\
\hline & Requested & $1.12(0.93,1.36)$ & $0.97(0.79,1.21)$ & & \\
\hline & Returned & $1.08(0.89,1.30)$ & $1.06(0.86,1.31)$ & & \\
\hline
\end{tabular}

Website logon, test request, and test return outcomes are dichotomized and restricted to participants who met previous test follow-through benchmarks (e.g., only participants who logged on to the website were included in the models for test request). Number of events and sample size for each of the logistic regression models are as follows: logged on 232/499, requested 204/232, returned 167/204. Test follow-through is modeled using ordinal logistic regression including all participants. Demographics adjustment covariates are ethnicity, education, and sunburn history. CI, confidence interval; demo. adj., demographics-adjusted; OR, odds ratio; unadj., unadjusted. 


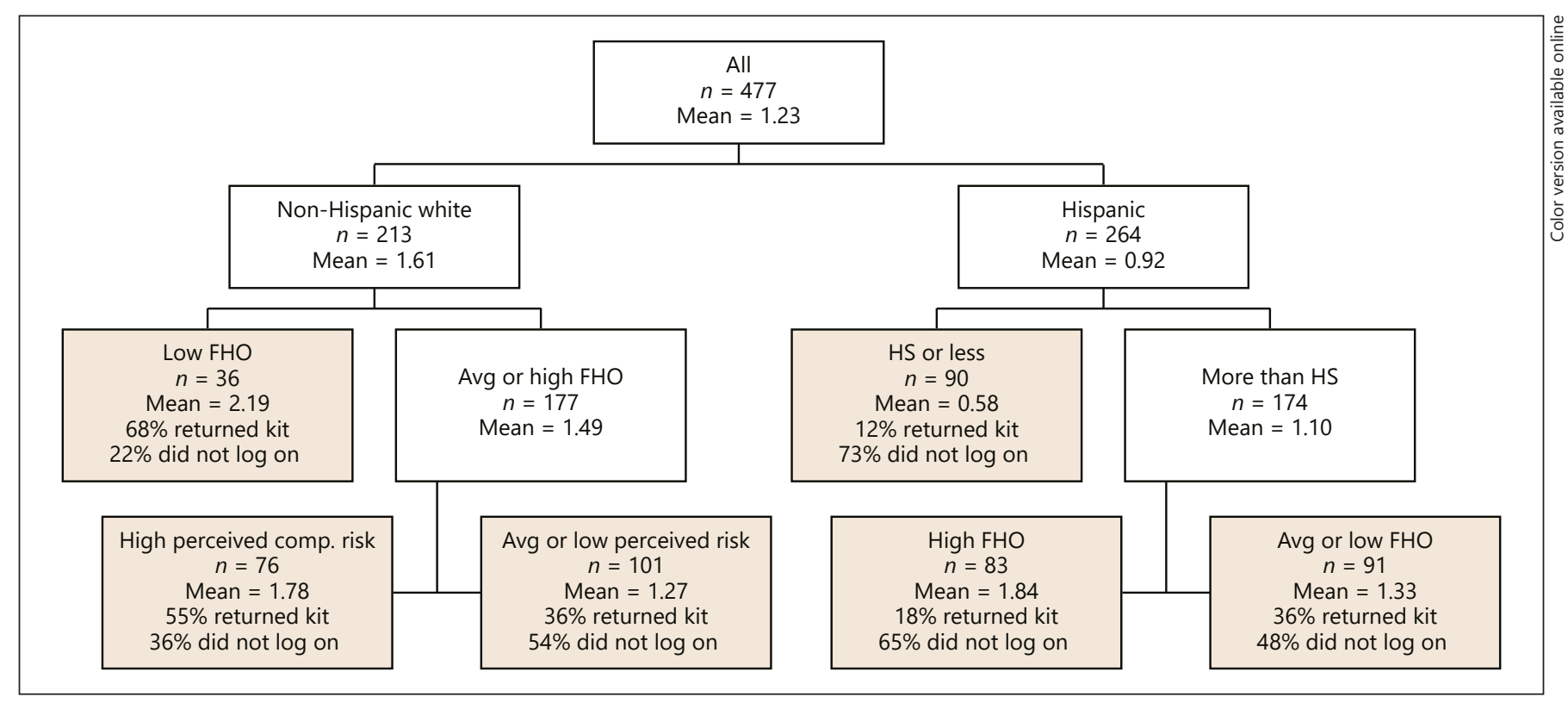

Fig. 1. Mean test follow-through by CART grouping results. Test follow-through is quantified as 0 (did not log on to website), 1 (logged on but did not request kit), 2 (requested kit but did not return), or 3 (returned kit). The "Hispanic" group $(n=264)$ also includes 31 participants who were of other races (neither white nor

\section{Discussion}

If genomic medicine is to have a robust impact on precision prevention and healthcare delivery, it must have broad reach [61]. Yet, translational genomic research has generally engaged white populations with high education and literacy levels $[24,62,63]$. In the current study, we examined psychosocial and cultural factors related to skin cancer genetic testing decisions in a diverse primary care population. Of 499 participants provided with an offer for skin cancer genetic testing, lower family health orientation and lower self-efficacy for skin cancer prevention were factors related to test interest, and findings varied among Hispanics and non-Hispanic whites. Such findings inform public health translation of skin cancer genetic risk information, including risk associated with $\operatorname{MC1R}[9,64]$, and highlight potential underlying barriers to dissemination and implementation of genomic technologies in the general population.

Considering each dichotomous outcome separately (website logon, requesting a test kit, and returning a test kit), we found that those with higher risk perceptions (two-level absolute; comparative), higher health literacy, lower family influence on health, and fewer misconceptions about skin cancer were more likely to log on to the
Hispanic). Perceived risk is comparative perceived risk. The results indicate six distinct risk groups, as shown in the shaded boxes. Avg, average; CART, classification and regression tree; FHO, family influence on health; HS, high school.

website to consider skin cancer genetic testing. Those with reduced cancer fatalism were more likely to order and return their test kit and to follow through with testing. Importantly, most of the effects of these psychosocial and cultural factors do not remain when adjusted for education, ethnicity, and sunburn history. Participants who reported they did not know their absolute risk (on a seven-point scale) were less likely to return their kit, even after adjustment for demographics; the "don't know" option for the two-level absolute risk item had a similar trend but was not significant. In the multivariable analyses, skin cancer prevention self-efficacy (feeling "capable" of performing risk reduction behaviors) remained significantly related to test kit request, over and above education, ethnicity, and sunburn history, though not to the ordinal follow-through outcome. Given the importance of demographic factors in our multivariable models, continued research examining populations diverse in terms of educational attainment and ethnicity is required. In the current work, skin cancer prevention self-efficacy may be an important barrier for following through with ordering a test.

Our findings indicate the importance of demographic characteristics in understanding the interest and outcomes of MC1R testing, despite our documented high levels of comprehensibility and access in Spanish as well 
as English [65]. Similarly, in another primary care population that was offered gene-environment risk information for colorectal cancer risk, Hall et al. [66] reported that race was a more important predictor of testing than perceptions of colorectal cancer risk, with African Americans much less likely to pursue testing than white participants. However, our CART models identified diverse predictors within different ethnic groups. For Hispanics, family influence on health was only important among those with more than a high school education. In contrast, among non-Hispanic whites, education was not an important predictor, but instead among those with higher family influence, comparative perceived risk was important. Of note, we had predicted that family influence on health, which was found to be a promoter of interest in learning about genes for common diseases in Detroit primary care [44], would also serve to promote interest and uptake of skin cancer genetic testing in the current context. More recently, Reid et al. [67] found that perceived family approval to learn genetic testing results was associated with intentions to learn results in a community sample offered whole-genome sequencing (e.g., ClinSeq). However, this study was cross-sectional, the outcomes were intentions rather than behavior, and the family support construct was more specific to learning results, rather than family support for maintaining health more broadly as was assessed here. This result indicates that a sense of independence from family health influence, or a reliance on personal decision-making regarding health, promotes interest and follow-through with skin cancer genetic testing. This may be because the choice of testing represents proactive health information seeking; the Internet provides engaged individuals with a direct and private method of accessing health information on a breadth of topics and represents one of the most frequent reasons that individuals consult the Internet. Additionally, we found that, compared to those with higher family influence on health, those with lower family influence had fewer misconceptions about skin cancer and higher health literacy, indicating that they may be relatively adept at health information seeking; however, they had more health system distrust, possibly indicating the value they place on private, Internet-mediated information seeking. A 2012 Pew Research Center Survey [68] found that most general Internet users (66\% of Hispanics, $73 \%$ of non-Hispanic whites) use the Internet to find health information. Hispanics are highly receptive to online cancer information [69], and in the case of personalized genomics, the Internet could provide needed privacy for individuals to consider the benefits and drawbacks of

Psychosocial Determinants of Skin Cancer Genetic Testing testing, apart from family influence. Ensuring access to those with high family influence on health may require a more family-focused intervention rather than individual consideration of testing.

We measured skin cancer threat using multiple measures of risk perceptions. In summary, we found, first, that those who enrolled versus refused participation in the study overall had higher perceived risk (seven-level absolute) and fewer "don't know" responses regarding risk perceptions, making outreach to those with lower perceived risk, or greater risk uncertainty, an important consideration in future skin cancer genomic research. Second, perceived risk was higher across all perceived risk measures in non-Hispanic whites compared to Hispanic participants, as were the rates of "don't know" risk perceptions, confirming the need for public health education about skin cancer risk in Hispanics. Third, those with higher risk perceptions (two-level absolute) were more likely to follow through with testing, and higher risk perceptions (comparative perceived risk) were a particularly important promoter of test follow-through among non-Hispanics whites. These findings confirm that risk perceptions promote testing and do so more in some groups than others. Taken together, these findings indicate that there are complex relations between illness threat and genetic testing in diverse populations; understanding these relations will maximize the reach of public health genomic research as well as clarity concerning groups that may be overlooked via study refusal, and testing refusal, in public health settings.

There were notable study strengths and limitations. The sample was large and more ethnically diverse than most translational genomics studies [24, 62, 63]. Also, the outcome measures were behavioral rather than self-reported. The trial was conducted in only one primary care health system in an academic setting and in a single location in the American southwest, which may not generalize fully to other primary care systems. Nonetheless, recruitment and study materials were in Spanish as well as English [65], setting the stage for dissemination of our $M C 1 R$ educational website and risk feedback materials in other setting. We found that study acceptors had higher perceived skin cancer risk and interest in learning about genetics compared to study refusers, and refusers also had a higher rate of reporting that they "did not know" their skin cancer risk compared to study acceptors, which anticipates uptake of real-world offers of genetic testing, yet may also limit our ability to generalize our findings to those with lower perceived skin cancer risk, those who report that they "do not know" their risk, or those who are less interested in learning about genes. Indeed, reach- 
ing those with reduced or uncertain risk perceptions is an important objective that deserves further research. However, the collection of these data, though minimal, among refusers as well as study acceptors was a study strength that allowed us to clarify these important factors related to study participation. The adjustment in language for our self-efficacy items midway through study completion limited the number we had available for analyses of either approach (e.g., "capable" vs. "confident" in reducing skin cancer risk); however, this modification was necessary to maintain participant satisfaction with these items. Although $M C 1 R$ conveys important information about inherited melanoma risk for a broad spectrum of individuals, concerns that $M C 1 R$ feedback may not prompt further behavior change in those who already perceive higher skin cancer risk, or potential negative consequences, such as development of a false sense of security among those who lack risk variants, are both valid concerns that require empirical examination. Finally, the incremental increase in risk for $M C 1 R$ is modest [70], making further translational work examining polygenic models and additional gene regions important future directions.

In summary, interest in $M C 1 R$ testing was relatively high in this diverse primary care population. Lower family influence on health was the most important cultural context factor related to test interest and may indicate that primary care patients interested in skin cancer genetic testing view themselves as proactive health seekers, independent from the need for family encouragement. Also, surprisingly, factors such as cancer fatalism and health system distrust were not related to test interest. These findings will help shape the public health translation of precision feedback for skin cancer risk, as feedback including genetic testing is anticipated to become more widely available in coming years via physicians and direct-to-consumer channels. There is a need to develop other ways of engaging those with lower educational attainment and for people of color, as well as those who experience more family influence on their health.

In conclusion, this study has advanced the public health translation of skin cancer genetic testing in providing insight into how such information may be received in populations unselected for risk status drawn from the general population. This examination of psychosocial and cultural determinants of interest and test uptake confirmed the importance of demographic factors, yet identified some important additional factors, including low family influence on health and self-efficacy for skin cancer prevention. We expect that evidence will continue to accumulate concerning the reliability and utility of a range of common genetic markers to inform precision skin cancer risk assessments, and that our findings will be relevant to working toward equitable use of such information in the general population.

\section{Acknowledgments}

We acknowledge the valued contributions of Vivian Rodriguez, PhD in carrying out this work, and Theodore Smith, BS in the preparation of the manuscript.

\section{Statement of Ethics}

Subjects (or their parents or guardians) provided written informed consent for study participation (online suppl. Appendix A). All study procedures and materials were approved by the institutional review board of the University of New Mexico.

\section{Disclosure Statement}

The authors have no conflicts of interest to declare.

\section{Funding Sources}

We acknowledge the support of NIH R01 CA181241 to J.L. Hay and M. Berwick (MPIs), as well as the facilities or services of the Behavioral Measurement and Population Sciences Shared Resource, a facility supported by the State of New Mexico and the University of New Mexico Cancer Center (P30 CA118100). We also acknowledge the MSK Support/Core Grant (P30 CA008748).

\section{Author Contributions}

All authors contributed to the design and implementation of the research, to the analysis of the results, and to the writing of the manuscript.

References

1 Roberts MC, Kennedy AE, Chambers DA, Khoury MJ. The current state of implementation science in genomic medicine: opportunities for improvement. Genet Med. 2017 Aug; 19(8):858-63.

2 Addie S, Olson S, Beachy S. Rapporteurs, Roundtable on Translating Genomic-Based Research for Health, Board on Health Sciences Policy, Health and Medicine Division, $\mathrm{Na}$ tional Academies of Sciences, Engineering, Medicine: Applying an Implementation Science Approach to Genomic Medicine Workshop Summary. Washington, DC: National Academies Press; 2016.
Hay et al. 
3 American Cancer Society. Cancer Facts \& Figures 2018 [June 21 2018]. Available from: https://www.cancer.org/research/cancerfacts-statistics/all-cancer-facts-figures/cancer-facts-figures-2018.html.

4 Rouhani P, Pinheiro PS, Sherman R, Arheart $\mathrm{K}$, Fleming LE, Mackinnon J, et al. Increasing rates of melanoma among nonwhites in Florida compared with the United States. Arch Dermatol. 2010 Jul;146(7):741-6.

5 Cockburn MG, Zadnick J, Deapen D. Developing epidemic of melanoma in the Hispanic population of California. Cancer. 2006 Mar; 106(5):1162-8

6 Hu S, Parmet Y, Allen G, Parker DF, Ma F, Rouhani $\mathrm{P}$, et al. Disparity in melanoma: a trend analysis of melanoma incidence and stage at diagnosis among whites, Hispanics, and blacks in Florida. Arch Dermatol. 2009 Dec;145(12):1369-74.

$7 \mathrm{Hu} \mathrm{S}$, Soza-Vento RM, Parker DF, Kirsner RS Comparison of stage at diagnosis of melanoma among Hispanic, black, and white patients in Miami-Dade County, Florida. Arch Dermatol. 2006 Jun;142(6):704-8.

8 Pollitt RA, Clarke CA, Swetter SM, Peng DH, Zadnick J, Cockburn M. The expanding melanoma burden in California Hispanics: importance of socioeconomic distribution, histologic subtype, and anatomic location. Cancer. 2011 Jan;117(1):152-61.

9 Kanetsky PA, Hay JL. Marshaling the Translational Potential of MC1R for Precision Risk Assessment of Melanoma. Cancer Prev Res (Phila). 2018 Mar;11(3):121-4.

10 Raimondi S, Sera F, Gandini S, Iodice S, Caini $\mathrm{S}$, Maisonneuve $\mathrm{P}$, et al. MC1R variants, melanoma and red hair color phenotype: a metaanalysis. Int J Cancer. 2008 Jun;122(12): 2753-60.

11 Gerstenblith MR, Shi J, Landi MT. Genomewide association studies of pigmentation and skin cancer: a review and meta-analysis. Pigment Cell Melanoma Res. 2010 Oct;23(5): 587-606.

12 Tagliabue E, Fargnoli MC, Gandini S, Maisonneuve P, Liu F, Kayser M, et al.; M-SKIP Study Group. MC1R gene variants and nonmelanoma skin cancer: a pooled-analysis from the M-SKIP project. Br J Cancer. 2015 Jul;113(2):354-63.

13 Pasquali E, García-Borrón JC, Fargnoli MC, Gandini S, Maisonneuve P, Bagnardi V, et al.; M-SKIP Study Group. MC1R variants increased the risk of sporadic cutaneous melanoma in darker-pigmented Caucasians: a pooled-analysis from the M-SKIP project. Int J Cancer. 2015 Feb;136(3):618-31.

14 Kanetsky PA, Panossian S, Elder DE, Guerry D, Ming ME, Schuchter L, et al. Does MC1R genotype convey information about melanoma risk beyond risk phenotypes? Cancer. 2010 May;116(10):2416-28.

15 Frieser MJ, Wilson S, Vrieze S. Behavioral impact of return of genetic test results for complex disease: systematic review and meta-analysis. Health Psychol. 2018 Dec;37(12):1134-44.
16 Bloss CS, Ornowski L, Silver E, Cargill M, Vanier V, Schork NJ, et al. Consumer perceptions of direct-to-consumer personalized genomic risk assessments. Genet Med. 2010 Sep; 12(9):556-66.

17 Kaphingst KA, Stafford JD, McGowan LD, Seo J, Lachance CR, Goodman MS. Effects of racial and ethnic group and health literacy on responses to genomic risk information in a medically underserved population. Health Psychol. 2015 Feb;34(2):101-10.

18 Sussner KM, Edwards TA, Thompson HS, Jandorf L, Kwate NO, Forman A, et al. Ethnic, racial and cultural identity and perceived benefits and barriers related to genetic testing for breast cancer among at-risk women of African descent in New York City. Public Health Genomics. 2011;14(6):356-70.

19 Torres S, Ramos M, Leverence R, Bowen D, Berwick M, Hay J. A pilot study of skin cancer risk reduction behaviors, cancer communication, and skin cancer beliefs in Hispanics. Calif J Health Promot. 2014;12:95-100.

20 Gammon AD, Rothwell E, Simmons R, Lowery JT, Ballinger L, Hill DA, et al. Awareness and preferences regarding BRCA1/2 genetic counseling and testing among Latinas and non-Latina white women at increased risk for hereditary breast and ovarian cancer. J Genet Couns. 2011 Dec;20(6):625-38.

21 Kinney AY, Gammon A, Coxworth J, Simonsen SE, Arce-Laretta M. Exploring attitudes, beliefs, and communication preferences of Latino community members regarding BRCA $1 / 2$ mutation testing and preventive strategies. Genet Med. 2010 Feb;12(2):105-15.

22 Vadaparampil ST, McIntyre J, Quinn GP. Awareness, perceptions, and provider recommendation related to genetic testing for hereditary breast cancer risk among at-risk Hispanic women: similarities and variations by sub-ethnicity. J Genet Couns. 2010 Dec;19(6): 618-29.

23 Pagán JA, Su D, Li L, Armstrong K, Asch DA. Racial and ethnic disparities in awareness of genetic testing for cancer risk. Am J Prev Med. 2009 Dec;37(6):524-30.

24 Suther S, Kiros GE. Barriers to the use of genetic testing: a study of racial and ethnic disparities. Genet Med. 2009 Sep;11(9):65562.

25 Viswanath K, Nagler RH, Bigman-Galimore CA, McCauley MP, Jung M, Ramanadhan S. The communications revolution and health inequalities in the 21st century: implications for cancer control. Cancer Epidemiol Biomarkers Prev. 2012 Oct;21(10):1701-8.

26 Lorence D, Park H. Group disparities and health information: a study of online access for the underserved. Health Informatics $J$. 2008 Mar; 14(1):29-38.

27 Lorence DP, Park H, Fox S. Racial disparities in health information access: resilience of the Digital Divide. J Med Syst. 2006 Aug;30(4): 241-9.

28 Rodríguez VM, Shuk E, Arniella G, González CJ, Gany F, Hamilton JG, et al. A qualitative exploration of Latinos' perceptions about skin cancer: the role of gender and linguistic acculturation. J Cancer Educ. 2017 Sep;32(3): 438-46.

29 Coups EJ, Stapleton JL, Manne SL, Hudson SV, Medina-Forrester A, Rosenberg SA, et al. Psychosocial correlates of sun protection behaviors among U.S. Hispanic adults. J Behay Med. 2014 Dec;37(6):1082-90.

30 Friedman LC, Bruce S, Weinberg AD, Cooper HP, Yen AH, Hill M. Early detection of skin cancer: racial/ethnic differences in behaviors and attitudes. J Cancer Educ. 1994;9(2):10510.

31 Pipitone M, Robinson JK, Camara C, Chittineni B, Fisher SG. Skin cancer awareness in suburban employees: a Hispanic perspective. J Am Acad Dermatol. 2002 Jul;47(1): $118-23$.

32 Robinson JK, Joshi KM, Ortiz S, Kundu RV. Melanoma knowledge, perception, and awareness in ethnic minorities in Chicago: recommendations regarding education. Psychooncology. 2011 Mar;20(3):313-20.

33 Hay JL, Berwick M, Zielaskowski K, White KA, Rodríguez VM, Robers E, et al. Implementing an Internet-Delivered Skin Cancer Genetic Testing Intervention to Improve Sun Protection Behavior in a Diverse Population: Protocol for a Randomized Controlled Trial. JMIR Res Protoc. 2017 Apr;6(4):e52.

34 Hay JL, Zielaskowski K, Meyer White K, Kaphingst K, Robers E, Guest D, et al. Interest and Uptake of MC1R Testing for Melanoma Risk in a Diverse Primary Care Population: A Randomized Clinical Trial. JAMA Dermatol. 2018 Jun;154(6):684-93.

35 Rogers RW. Cognitive and physiological processes in attitude change: A revised theory of protection motivation. In: Cacioppo J, Petty R, editors. Social Psychophysiology. New York: Guilford Press; 1983. p. 153-76.

36 Ashida S, Wilkinson AV, Koehly LM. Social influence and motivation to change health behaviors among Mexican-origin adults: implications for diet and physical activity. Am J Health Promot. 2012 Jan-Feb;26(3):176-9.

37 Pasick RJ, Barker JC, Otero-Sabogal R, Burke NJ, Joseph G, Guerra C. Intention, subjective norms, and cancer screening in the context of relational culture. Health Educ Behav. 2009 Oct;36(5 Suppl):91S-110S

38 Armstrong K, Putt M, Halbert CH, Grande D, Schwartz JS, Liao K, et al. The influence of health care policies and health care system distrust on willingness to undergo genetic testing. Med Care. 2012 May;50(5):381-7.

39 Bernhardt JM, Lariscy RA, Parrott RL, Silk KJ, Felter EM. Perceived barriers to Internetbased health communication on human genetics. J Health Commun. 2002 Jul-Sep;7(4): $325-40$

40 Espinosa de Los Monteros K, Gallo LC. The relevance of fatalism in the study of Latinas' cancer screening behavior: a systematic review of the literature. Int J Behav Med. 2011 Dec;18(4):310-8. 
41 Roman C, Lugo-Somolinos A, Thomas N. Skin cancer knowledge and skin self-examinations in the Hispanic population of North Carolina: the patient's perspective. JAMA Dermatol. 2013 Jan;149(1):103-4.

42 Kutner M, Greenberg E, Jin Y, Paulsen C. The Health Literacy of America's Adults: Results From the 2003 National Assessment of Adult Literacy (NCES 2006-483). U.S. Department of Education. Washington, DC: National Center for Education Statistics; 2006.

43 National Cancer Institute. Anyone can get skin cancer. Bethesda, MD: National Cancer Institute; 2011.

44 Hay J, Kaphingst KA, Baser R, Li Y, HensleyAlford S, McBride CM. Skin cancer concerns and genetic risk information-seeking in primary care. Public Health Genomics. 2012; 15(2):57-72.

45 Fitzpatrick TB. The validity and practicality of sun-reactive skin types I through VI. Arch Dermatol. 1988 Jun;124(6):869-71.

46 Witte K, Cameron KA, McKeon JK, Berkowitz JM. Predicting risk behaviors: development and validation of a diagnostic scale. J Health Commun. 1996 Oct-Dec;1(4):317-41.

47 Nelson DE, Kreps GL, Hesse BW, Croyle RT, Willis G, Arora NK, et al. The Health Information National Trends Survey (HINTS): development, design, and dissemination. J Health Commun. 2004 Sep-Oct;9(5):443-60; discussion 81-4.

48 Weinstein ND. Unrealistic optimism about susceptibility to health problems. J Behav Med. 1982 Dec;5(4):441-60.

49 Waters EA, Hay JL, Orom H, Kiviniemi MT, Drake BF. "Don't know" responses to risk perception measures: implications for underserved populations. Med Decis Making. 2013 Feb;33(2):271-81.

50 Hay JL, Oliveria SA, Dusza SW, Phelan DL, Ostroff JS, Halpern AC. Psychosocial mediators of a nurse intervention to increase skin self-examination in patients at high risk for melanoma. Cancer Epidemiol Biomarkers Prev. 2006 Jun;15(6):1212-6.

51 Bandura A. Social foundations of thought and action: A social cognitive theory. Englewood Cliffs, NJ, US: Prentice-Hall, Inc; 1986.

52 Shea JA, Micco E, Dean LT, McMurphy S, Schwartz JS, Armstrong K. Development of a revised Health Care System Distrust scale. J Gen Intern Med. 2008 Jun;23(6): 727-32.

53 Powe BD. Cancer fatalism among elderly Caucasians and African Americans. Oncol Nurs Forum. 1995 Oct;22(9):1355-9.

54 National Cancer Institute. Health Information National Trends Survey 2007 [Accessed Oct 1, 2013]. Available from: http://hints.cancer.gov.

55 Chew LD, Griffin JM, Partin MR, Noorbaloochi S, Grill JP, Snyder A, et al. Validation of screening questions for limited health literacy in a large VA outpatient population. J Gen Intern Med. 2008 May;23(5):561-6.

56 Chew LD, Bradley KA, Boyko EJ. Brief questions to identify patients with inadequate health literacy. Fam Med. 2004 Sep;36(8): 588-94.

57 Agresti A. Categorical Data Analysis. 2nd ed. Hoboken, NJ: John Wiley \& Sons, Inc.; 2002.

58 Breiman L. Classification and Regression Trees. New York: Routledge; 1984.

59 Breiman L. Random forests. Mach Learn. 2001;45(1):5-32.

60 Liaw A, Wiener M. Classification and Regression by randomForest. R News. 2002;2:18-22.

61 Kaphingst KA, Goodman MS. Importance of race and ethnicity in individuals' use of and responses to genomic information. Per Med. 2016 Jan;13(1):1-4.

62 Bloss CS, Schork NJ, Topol EJ. Effect of direct-to-consumer genomewide profiling to assess disease risk. N Engl J Med. 2011 Feb; 364(6):524-34.

63 Hensley Alford S, McBride CM, Reid RJ, Larson EB, Baxevanis AD, Brody LC. Participation in genetic testing research varies by social group. Public Health Genomics. 2011;14(2): 85-93.

64 Smit AK, Espinoza D, Newson AJ, Morton RL, Fenton G, Freeman L, et al. A Pilot Randomized Controlled Trial of the Feasibility, Acceptability, and Impact of Giving Information on Personalized Genomic Risk of Melanoma to the Public. Cancer Epidemiol Biomarkers Prev. 2017 Feb;26(2):21221.

65 Rodríguez VM, Robers E, Zielaskowski K, Javier González C, Hunley K, Kaphingst KA, et al. Translation and adaptation of skin cancer genomic risk education materials for implementation in primary care. J Community Genet. 2017 Jan;8(1):53-63.

66 Hall MJ, Manne SL, Myers RE, Keenan EM, Balshem AM, Weinberg DS. Predictors of patient uptake of colorectal cancer gene environment risk assessment. Genome Med. 2012 Nov; $4(11): 92$.

67 Reid AE, Taber JM, Ferrer RA, Biesecker BB, Lewis KL, Biesecker LG, et al. Associations of perceived norms with intentions to learn genomic sequencing results: roles for attitudes and ambivalence. Health Psychol. 2018 Jun; 37(6):553-61.

68 Fox S, Duggan M. Health Online 2013. Available from: http://pewinternet.org/Reports/2013/Health-online/Summary-ofFindings.aspx.

69 Selsky C, Luta G, Noone AM, Huerta EE, Mandelblatt JS. Internet access and online cancer information seeking among Latino immigrants from safety net clinics. J Health Commun. 2013;18(1):58-70.

70 Cust AE, Drummond M, Kanetsky PA, Goldstein AM, Barrett JH, MacGregor S, et al.; Australian Melanoma Family Study Investigators; Leeds Case-Control Study Investigators. Assessing the Incremental Contribution of Common Genomic Variants to Melanoma Risk Prediction in Two Population-Based Studies. J Invest Dermatol. 2018 Dec;138(12): 2617-24. 